\title{
Rheological Properties of Recycled Aggregate Concrete
}

\section{Using Superplasticizers}

\author{
Sandrine Braymand ${ }^{1}$, Pierre François ${ }^{1}$, Françoise Feugeas ${ }^{2}$ and Christophe Fond ${ }^{1}$ \\ 1. ICube, Department of Mechanic, University of Strasbourg, CNRS, Strasbourg 67000, France \\ 2. ICube, INSA de Strasbourg, CNRS (National Center for Scientific Research), Strasbourg 67081, France
}

\begin{abstract}
The mechanical properties of recycled aggregates concrete from demolition have been studied for several years. It has been documented that rheological properties of these concrete are generally affected by use of recycled aggregates. They could present mechanical properties less affected by the presence of recycled aggregates if the initial concrete were of good quality. However, manufacturing problems, mainly attributed to the angular character of these aggregates and to the granulometry of recycled sand, limit their industrial use. The worth point of this study consists in the optimization of the concrete formulation using specific admixture, adapted to this aggregates in order to facilitate its manufacturing. It shows that the new generation of superplasticizers containing some copolymer polycarboxylate makes it possible to significantly improve the fluidity of the recycled aggregates concrete in its fresh state. The aim of this research is to control rheological properties of fresh recycled aggregates concrete with fine and coarse recycled aggregates to limit the negative influence of aggregates on mechanical properties of concrete.
\end{abstract}

Key words: Superplasticizer, recycled aggregate, concrete, workability, viscosity, mechanical strength, grading.

\section{Introduction}

The development of recycled aggregates concrete in the current context of sustainable development is a lot at stake in terms of economy and environment for the sector of building [1, 2]. The use of demolished concrete as aggregate for concrete requires checking that characteristics of these aggregates stay acceptable regarding standards. It is often considered that they are worse than those of natural aggregates, mainly due to the presence of mortar and residual impurities in recycled aggregates. It causes the decrease in mechanical strength [3]. Concrete manufactured using recycled aggregates could have mechanical properties equal to the natural aggregate concrete provided that the parent concrete is of good quality with high mechanical properties [4, 5]. A threshold of substitution quantity can be observed, beyond this quantity, a decrease of the mechanical properties can

Corresponding author: Sandrine Braymand, assistant professor, research fields: civil engineering, material science and recycling material. E-mail: s.braymand@unistra.fr. be observed $[6,7]$. However, the mechanical strength of recycled aggregates is not the only one reason for this decreasing [8-12]. Manufacturing problems encountered limit their industrial use, mainly attributed both to the high water absorption and the angular character of these aggregates and to the particle size distribution of recycled sand [13, 14].

The presence of recycled fine aggregates causes extra water demand $[15,16]$, their replacement by natural sand may facilitate the workability of concrete and then contributes to enhance mechanical properties $[9,17]$. This point of view is sometimes discussed [14].

Recently, the development of new superplasticizers and their use to improve workability of recycled aggregates concrete lead to other conclusions. Especially, the systematic removing of fine elements can be avoided and allows to maintain these fine elements which improve the porosity of the concrete [18].

In the first part of this study, the properties of concrete formulated with the totality of aggregates 
issued from demolished concrete were analyzed. The aim of this first part was to confirm the possibility of obtaining a concrete presenting equal mechanical strengths to those of natural aggregates concrete. As the results indicate that a high quantity of superplasticizer $(3 \%)$ is needed to obtain a satisfactory workability of recycled aggregate concrete, a study of screening of admixtures was performed. For this purpose, rheological properties of mortar made up of fine elements are evaluated, after identifying the most effective admixtures in terms of workability and spread.

\section{Materials and Methods}

\subsection{Aims and Steps of Research}

Three successive trial campaigns were carried out in order to meet the following requirements:

- Firstly, to compare the mechanical properties of three different types of concrete: traditional concrete (natural aggregate); mixed concrete (natural sand and recycled coarse aggregates); recycled concrete (recycled aggregate). The workability of these concrete were also controlled;

- Secondly, to identify the admixture, in particular which type(s) of superplasticizer(s) is the best choice to use with recycled sand. This investigation was carried out on mortar;

- Finally, to analyze the rheological behavior of a recycled sand mortar formulated with admixture and to identify the action of the admixture on the constituents of mortar with fine recycled aggregates.

\subsection{Materials and Specimens}

\subsubsection{Properties of Recycled Aggregates}

The aggregates of the study come from crushed demolition materials (concrete). They are produced by a company based in Alsace (France). No information was available concerning properties or ages of parent concrete.

The material was split by sifting it into three different categories: $0 / 6.5,6.5 / 13$ and 13/20 mm
(Fig. 1).

Grading tests were carried out according to NF EN 933-1 Standards - granulometric analysis by sifting, and NF P 94-057-sedimentometry. Recycled sand has a discontinuous grading curve, with a fineness modulus indicating that sand would be described as rather coarse (ratio value: 3.05 3.2). Complete granular skeleton of concrete $(0 \sim 20 \mathrm{~mm})$ was determined following Dreux-Gorisse method for both types of aggregates (natural and recycled).

The cleanliness of this sand shows that it is possible to consider it as "clean". The sedimentometry tests which were carried out on the two sands supplement this result by indicating that recycled sand contains relatively important fine elements with a fraction of $0.02 / 0.08 \mathrm{~mm}$. The recycled gravel, just like the fine gravel, follows a quasi linear granulometry curve (in $\log$ representation in Fig. 1). The granulometry of natural gravel is richer in intermediate particle sizes of aggregates $(12.5 \sim 16 \mathrm{~mm})$ than recycled gravel.

The absolute density and the bulk density have been tested according to the NFP 18-558 Standard-absolute density of fine elements. The absolute density of the recycled concrete aggregates is lower $\left(2.4 \sim 2.6 \mathrm{~g} / \mathrm{cm}^{3}\right)$ than natural aggregate $\left(2.6 \sim 2.7 \mathrm{~g} / \mathrm{cm}^{3}\right)$. The specific surface of recycled sand $0 / 0.063 \mathrm{~mm}$ is lower than that of cement $\left(1,950 \mathrm{~g} / \mathrm{cm}^{2}\right)$.

The mechanical performances of recycled aggregates have been tested following NF EN 1097-2

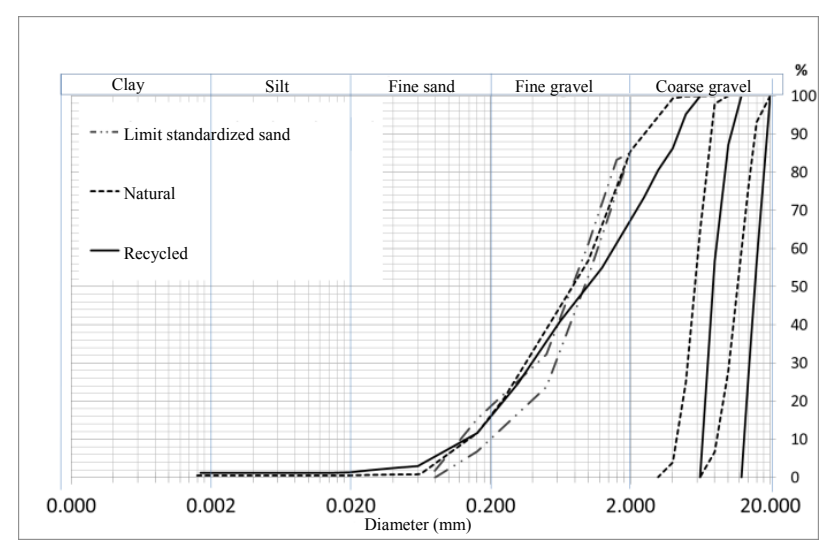

Fig. 1 Granulometry analysis of recycled and natural aggregates. 
Standard. Los Angeles test results indicate values of $25 \%$ and $15 \%$ respectively for recycled aggregates and natural aggregates. Both aggregates can then be considered of Category A, the best one.

\subsubsection{Concrete and Mortar Compositions}

The concrete specimens tested in compressive strength (natural, mix and recycled) were formulated to obtain $37 \mathrm{MPa}$ of compressive strength at 28 days of age. Their compositions are given in Table 1.

A superplasticizer admixture of polymeric type (vinyl acrylic copolymer) was used in order to reach equal fluidity for the three concretes. In this way, it has been found that 3\% admixture (mass cement ratio) was necessary to reach a satisfactory workability for the recycled concrete aggregate. This admixture is usually used for ready-mixed concrete. An ordinary Portland cement designed CEM I-52.5N was used with containing other $95 \%$ of clinker $(\mathrm{K})$.

The recycled mortar compositions (Table 2) were formulated in order to compare the efficiency of several superplasticizers. For the remainder of the study (screening of admixture), it was not possible to use the same type of admixture (vinyl acrylic copolymer) because his fabrication was stopped. Compositions and properties of admixtures (commercially available) tested for this screening are given in Table 3.

CEM II/B-(L-S)-32.5R was used. This cement is constituted with clinker (K), limestone (L) and blast furnace slag (S). The clinker content is included between $65 \%$ and $79 \%$.

The fine recycled aggregate mortars were studied in order to characterize rheological behavior of mortar added with recycled fines. Compositions are given in Table 4. In this part of study, only Admixtures A, F and $\mathrm{G}$ were used.

\subsection{Methods of Investigation}

\subsubsection{Comparison of Concrete}

In order to be able to carry out comparisons between the various compositions of concrete, the following tests were carried out: tension by bending

Table 1 Concrete compositions.

\begin{tabular}{llll}
\hline Components & Traditional T $\left(\mathrm{kg} / \mathrm{m}^{3}\right)$ & Mix M $\left(\mathrm{kg} / \mathrm{m}^{3}\right)$ & Recycled R $\left(\mathrm{kg} / \mathrm{m}^{3}\right)$ \\
\hline Cement CEM I-52.5N & 350 & 350 & 350 \\
Admixture & 0 & 2.625 & 10.5 \\
Water & 194 & 180 & 165 \\
Natural sand & 685 & 759 & 0 \\
Recycled sand & 0 & 0 & 769 \\
Natural gravel & 1176 & 0 & 0 \\
Recycled gravel & 0 & 967 & 866 \\
\hline
\end{tabular}

Table 2 Grout and mortar compositions.

\begin{tabular}{lll}
\hline Compositions (Cement CEM II/B-(L-S)-32.5 R) & Grout & Mortar \\
\hline Water/cement (ratio) & 0.28 & 0.30 \\
Admixture (percentage of cement) & 1.5 & 1.5 \\
Sand/cement (ratio) & 0 & 2.5 \\
\hline
\end{tabular}

Table 3 Types of used admixtures.

\begin{tabular}{lll}
\hline Name & Chemical base & Properties \\
\hline A & Modified polycarboxylate & Plasticizer, high water reducer, long preservation of workability \\
B & Modified phosphonate & Superplasticizer, very long preservation of workability \\
C & Polycarboxylate copolymers & Superplasticizer, high water reducer, increase workability time \\
D & Naphtalens & Superplasticizer, high water reducer, normal preservation of workability \\
E & Polymelamine & Superplasticizer, high water reducer, improve concrete compacity \\
F & Modified polycarboxylate & Superplasticize, high water reducer, weak preservation of workability \\
G & Modified ether polycarboxylate & Superplasticizer, high water reducer, long preservation of workability \\
\hline
\end{tabular}


Table 4 Fines mortar compositions.

\begin{tabular}{lll}
\hline Compositions (Cement CEM II/B-(L-S)-32.5 R) & Grout & Mortar \\
\hline Water/cement (ratio-mass) & 0.45 & 0.45 \\
Admixture (percentage of mass of cement) & 1 & 1 \\
Sand/cement (ratio-mass) & 0 & 0.4 \\
\hline
\end{tabular}

(NF EN 12 390-6 Standard) and compression (NF EN

12 390-3 Standard). Workability of concrete was controlled by Abrams cone test (NF P 18-423 Standard).

\subsubsection{Workability of Mortar-Screening}

Two tests, a slump test (collapse) and a flow test (spread out), were performed with a mini cone to measure the workability of the mortar. The "mortar mini slump test" is inspired from a rheological testing device: the Abrams slump test. It allows to determine the workability of the mortar. The mini slump test dimensions respect the $1 / 3$ of those of the Abrams slump test used to measure the workability of the concrete according to NF EN 12350-2 Standard.

\subsubsection{Viscosity of Fine Recycled Aggregate Mortar}

A shear stress imposed viscosimeter with coaxial cylinders (coquette geometries) was used coupled with various measuring instruments allowing for space-gaps of different sizes. The maximum shear torque of the viscometer designed by $\Omega$ max of the viscometer was $2 \mathrm{Ncm}$. The cylinder had an exterior diameter of $6 \mathrm{~cm}$. For the internal diameter, two types of tools were used for the stress shearing measurement: a cylindrical tool and a "vane" tool (with wings) in order to prevent wall slipping. Dimensions were a radius of $2.7 \mathrm{~cm}$ and height of $6.9 \mathrm{~cm}$.

\section{Results and Discussions}

\subsection{Workability and Compressive Strength of Concrete}

A large quantity of admixture (3\%) had to be added to the recycled aggregate concrete to take into account the following points:

- fine aggregates in recycled sand adsorb large amounts of water;
- recycled concrete aggregates can absorb more water than natural aggregates due to their higher porosity;

- recycled aggregates are crushed and reduce the workability of concrete.

A slump class $\mathrm{S} 2$ (50 90 $\mathrm{mm}$ of slump) according to the EN 206-1 Standard was reached. The manufacturing of the three concretes could thus be realized by preserving an objective of equal resistance as shown in Fig. 2 (47 MPa of compressive strength for the mix and recycled concrete and $44 \mathrm{MPa}$ for traditional concrete at 28 days of age).

Furthermore, observation of concrete surface (Fig. 3)

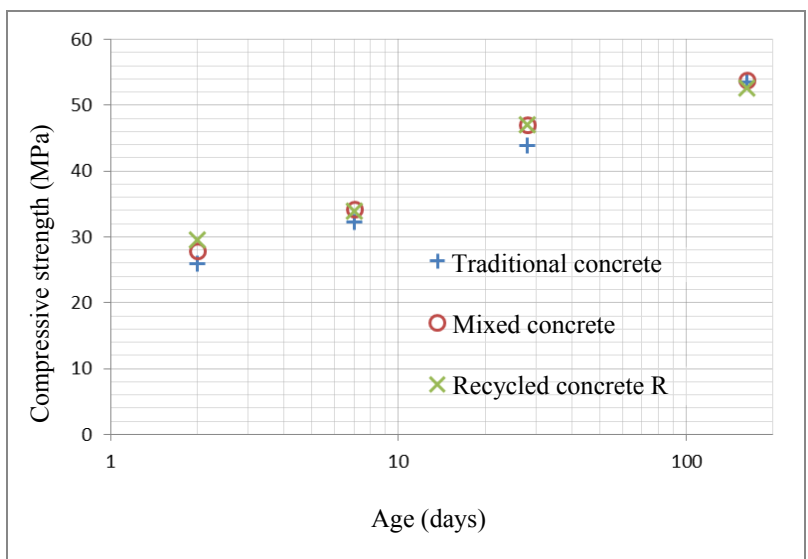

Fig. 2 Compressive strengths of the studied concretes.
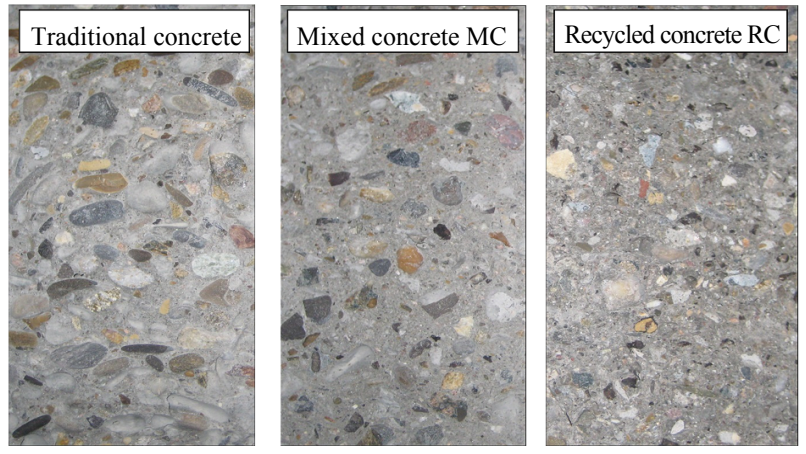

Scale: $20 \mathrm{~mm}$

Fig. 3 Fracture topographies of studied concrete. 
shows a strong link between recycled aggregate and cement paste: old concrete and new concrete cannot be distinguished, at least at this scale. This observation can explain the good mechanical strength obtained with recycled concrete.

As high amount of admixture was necessary, an in-depth study was necessary in order to compare efficiency of admixture and to highlight the effect of admixture on recycled sands and recycled fine elements.

\subsection{Comparison of Admixture Efficiency on Mortar Workability}

Slump and spread tests were carried out on recycled mortar in order to settle on admixture for the rest of the study. These tests have been performed on mortars selected according to their granular size. Results are presented in Fig. 4. The gain are calculated from the results on mixing without admixture. All admixtures present a good efficiency on coarse sand $(3.15 / 6.5 \mathrm{~mm})$. The efficiency is variable depending on the type of admixture for grout and fine mortars $(0 / 1.5 \mathrm{~mm})$. Furthermore, the action of admixture is enhanced on slump compared to spread/flow for fine mortar.

At the end of this screening, three superplasticizers, with the same chemical base (polycarboxylate), have been chosen. It was decided to choose admixtures presenting different levels of efficiency: high (F), good (G) and medium (A), and to focus on the efficiency of these admixtures on fine recycled aggregate mortar viscosity.

\subsection{Viscosity of Recycled Fine Aggregates Mortar}

Only the instantaneous results of measurement (after the beginning of mixing) will be presented. Measurements at $20 \mathrm{~min}$ are not significant, due to an important segregation (loss of rheological stability).

\subsubsection{Cement Grout}

Only three out of the seven tested admixtures were retained for this study. The following lines in Fig. 5 describe the behavior of cement grout with or without admixture. The behavior observed for the cement grout is that of shear thickened fluids. The Bingham model gives an approximation of the shear stress for the cement grout without admixture. On adding the superplasticizers, a reduction of the shear stress threshold occurred. Absolute viscosity (viscosity obtained at high speed) also decreases with the addition of an admixture.

The three admixtures used seem to have the same effectiveness on cement. This result is similar to that observed during the mini cone test carried out at the time of the second trial run. The rheological behavior observed is modified by addition of admixture. A constant low value of the shear stress is observed when velocity is low, then thickening appears when the velocity increases, depending on the type of admixture.

3.3.2 Recycled Fine Aggregates Mortar

The results (Fig. 6) indicate that the fines recycled

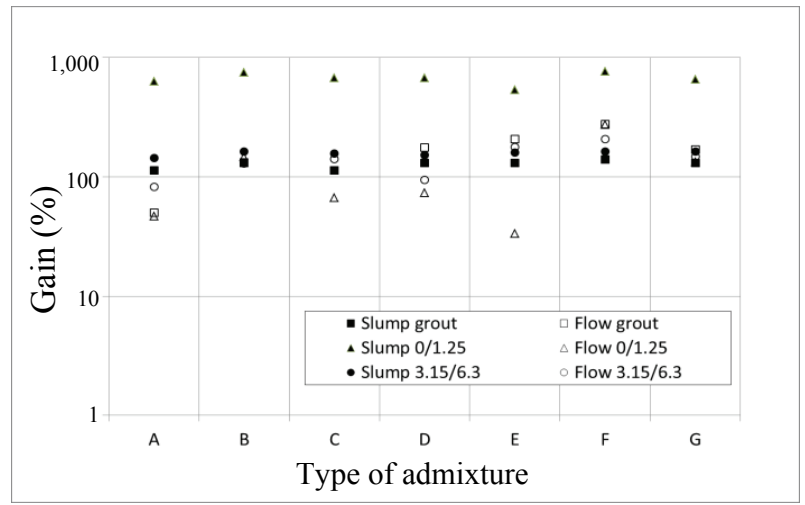

Fig. 4 Slump and flow tests on mortar and grout.

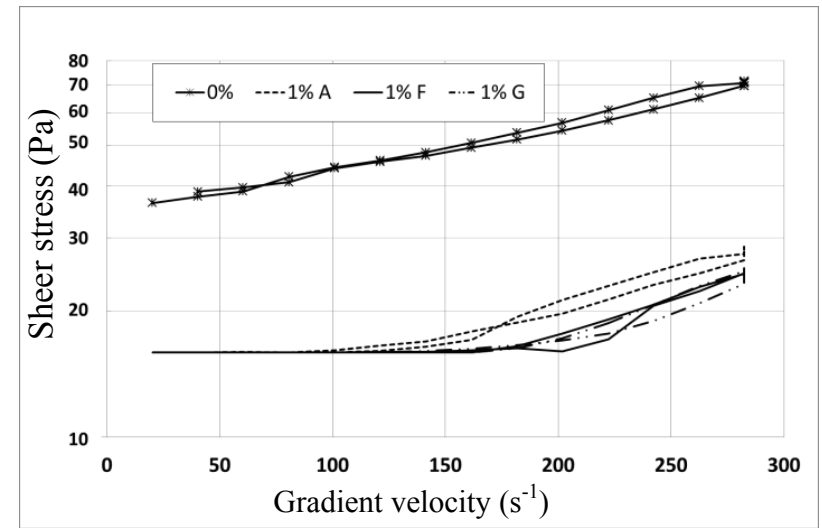

Fig. 5 Rheogram of the compositions of cement grout with or without admixtures. 


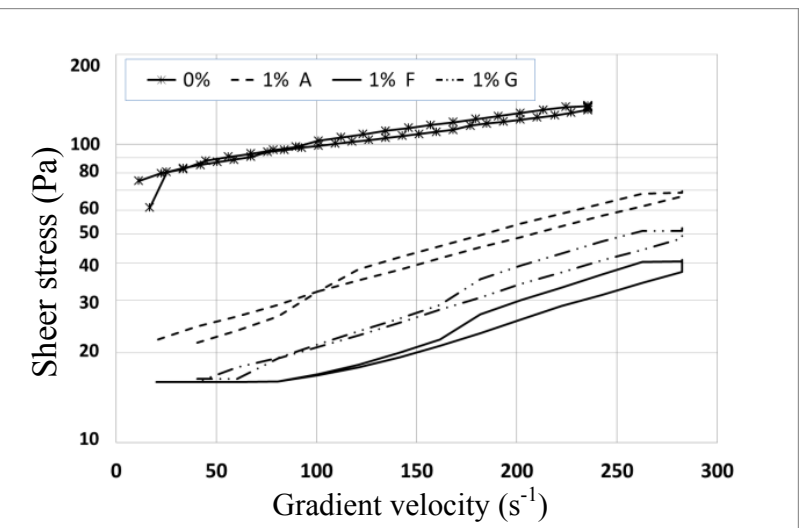

Fig. 6 Rheogram of the composition of mortars with or without admixture.

aggregates mortar with or without admixture are plastic and follow a linear Bingham model. As expected, on adding the superplasticizers, a reduction of the shear stress threshold occurred. Nevertheless, contrary to the cement paste, the effectiveness of the admixtures seems to be different, depending on the type of admixtures.

The two Admixtures $\mathrm{F}$ and $\mathrm{G}$ have an immediate effectiveness slightly more important than that observed using the A product. This result is still in conformity with that presented in Section 3.2.

\section{Conclusions and Perspectives}

It is often quoted that there is a negative influence of cement paste (present in the composition of the recycled aggregates) on rheological characteristics at the fresh state and on the mechanical properties of concrete composed of recycled aggregates. It has shown in the present study that it was possible to obtain concrete composed of recycled aggregates with mechanical performances close to those obtained with natural aggregate when the workability is well optimized by use of superplasticizers.

This study was directed towards the development of a formulation of concrete-formulated with fine and coarse recycled aggregates-to determine the admixtures adapted to the recycled aggregates. The new generation of superplasticizers composed of copolymer seems to solve the problem of workability (slump and flow tests) of the recycled aggregates concrete. This solution is preferable to that which consists in substituting the recycled sand by natural sand, the granular skeleton obtained by this substitution then being irregular. It is even possible to obtain higher mechanical resistances with a recycled aggregate concrete than with a natural aggregate concrete (compressive strength). This improvement could be attributed to the IZT (interfacial zone of transition) of recycled concrete. This interface could be improved thanks to a residual hydraulic reactivity of the recycled aggregates (reactivity of the cement paste from crushed concrete). But as the age and composition of parent concrete is not known, reactivity of recycled aggregate should be studied in further research. Further studies should tell us more information on the physical and mechanical properties of recycled aggregate concrete (issued from crushed concrete) in order to confirm and explain these first conclusions.

An extensive research of this study was orientated towards the comprehension of the rheological behavior of recycled aggregate mortar mixed with superplasticizers. It shows that polycarboxylate copolymers or that modified polycarboxylate polymers were the most efficient to improve rheological properties of mixing constituted of sands and of fine elements. A screening of superplasticizers could be performed on concrete in further research to confirm these results in presence of coarse aggregate.

Future research on this topic needs to be conducted with the aim of selecting an admixture which will lead to obtaining a concrete presenting all of the characteristics comparable with the standardized concrete (maintaining workability, mechanical strength, dilatations, creep, porosity and durability). This future research could examine an extensive screening of superplasticizers including several types of chemical base of the admixtures. Identifying the appropriate admixtures would contribute in solving the following problems:

- keeping of the fine elements of the recycled 
aggregates in the composition which appears possible under condition of a thorough knowledge of their size, origin, composition and potential reactivity;

- taking into account of the angular shape and porosity of the fine gravels and coarse gravels;

- consideration of the potential problems of durability generated by the use of recycled aggregates and the inhibition of these problems (for example, alkali aggregate reaction).

It is also essential to control the quantity and the quality of cement paste present in the parent concrete (crushed) to understand their influence on the properties of recycled aggregate concrete.

\section{Acknowledgments}

The authors wish to express their gratitude to the European Community for their contribution to this research project, through the program Interreg IV (Cross Border Areas of the Rhin Program) entitled "To Increase the Knowledge Transfer in Sustainable Civil Engineering".

\section{References}

[1] Braymand, S. 2012. "Study of Rheological and Mechanical Properties of Recycled Brick Aggregate Concrete." Presented at WASCON (Waste Material in Construction) 2012, Göterburg.

[2] Serres, N., Braymand, S., and Feugeas, F. 2015. "Environmental Evaluation of Concrete Made from Recycled Concrete Aggregate Implementing Life Cycle Assessment (LCA)." Journal of Building Engineering. (submitted)

[3] Mas, B., Cladera, A., Del Olmo, T., and Pitarch, F. 2012. "Influence of the Amount of Mixed Recycled Aggregates on the Properties of Concrete for Non Structural Use." Construction and Building Materials 27: 612-22.

[4] Debieb, F., Courard, L., Kenai, S., and Degeimbre, R. 2010. "Mechanical and Durability Properties of Concrete Using Contaminated Recycled Aggregates." Cement and Concrete Composites 32: 421-6.

[5] Xiao, J., Huang, Y., Yang, J., and Zhang, C. 2012. "Mechanical Properties of Confined Recycled Aggregate Concrete under Axial Compression." Construction and Building Materials 26: 591-603.

[6] Evangelista, L., and de Brito, J. 2007. "Mechanical Behaviour of Concrete Made with Fine Recycled
Concrete Aggregates." Cement and Concrete Composites 29: 397-401.

[7] Etxeberria, M., Vázquez, E., Marí, A., and Barra, M. 2007. "Influence of Amount of Recycled Coarse Aggregates and Production Process on Properties of Recycled Aggregate Concrete." Cement and Concrete Research 37: 735-42.

[8] Ajdukiewicz, A., and Kliszczewicz, A. 2002. "Influence of Recycled Aggregates on Mechanical Properties of HS/HPC." Cement and Concrete Composites 24: 269-79.

[9] Tu, T. Y., Chen, Y., and Hwang, C. 2006. "Properties of HPC with Recycled Aggregates." Cement and Concrete Research 36: 943-50.

[10] Rao, A., Jha, K. N., and Misra, S. 2007. "Use of Aggregate from Recycled Construction and Demolition Waste in Concrete." Resources Conservation and Concrete 50: 71-81.

[11] Maier, P. L., and Durham, S. A. 2012. "Beneficial Use of Recycled Materials in Concrete Mixture." Construction and Building Materials 29: 428-37.

[12] Tam, V. W. Y., Wang, K., and Tam, C. M. 2008. "Assessing Relationships among Properties of Demolished Concrete, Recycled Aggregate and Recycled Aggregate Concrete Using Regression Analysis.” Journal of Hazardous Materials 152: 703-14.

[13] Soutsos, M. N., Tang, K., and Millard, S. G. 2011. "Concrete Building Blocks Made with Recycled Demolition Aggregate." Construction and Building Materials 25: 726-35.

[14] Braymand, S. 2010. "Influence de L'Utilisation de Granulats Recyclés sur les Propriétés Rhéologiques et Physiques des Bétons (Influence of Recycled Aggregate Use on Rheological and Physical Properties of Concrete)." Presented at Congrès Matériaux (Material Congress) 2010, Nantes. (in French)

[15] Westerholm, M., Lagerblad, B., Silwerbrand, J., and Forssberg, E. 2008. "Influence of Fine Aggregate Characteristics on the Rheological Properties of Mortars." Cement and Concrete Composites 30: 274-82.

[16] Yaprak, H., Aruntas, H., Demir, I., Simsek, O., and Durmus, G. 2011. "Effects of the Fine Recycled Concrete Aggregate on the Concrete Properties." International Journal of Physical science 6: 2455-61.

[17] Hansen, T. C. 1992. Recycling of Demolished Concrete and Masonry. RILEM (International Union of Laboratories and Experts in Construction Materials) report, London Chapman \& Hall, E \& FN Spon.

[18] Pereira, P., Evangelista, L., and de Brito, J. 2012. "The Effect of Superplasticizers on the Workability and Compressive Strength of Concrete Made with Fine Recycled Concrete Aggregates." Construction and Building Materials 28: 722-9. 